\title{
Foreword: Aging in Muslim and Middle Eastern Populations
}

\author{
Mustafa Z. Younis
}

Published online: 18 December 2014

(C) Springer Science+Business Media New York 2014

I am very pleased to introduce this Special Issue of Aging International on "Aging in Muslim and Middle Eastern Populations." We hope this Special Issue to be both interesting and provocative, and that the articles in it will provoke further research, case studies, and demonstrations in the field of Healthcare Policy.

I gratefully acknowledge valuable guidance and feedback provided by William Ward, University of South Florida, Hongtu Chen, Harvard University; Sue Levkoff, University of South Carolina; Adnan Kisa, Zirve University, Turkey; and Yucuf Celick, Hacettepe University, Turkey. I thank Carolyn Meyers, President of Jackson State University, and James Renick, the Senior Vice President of Academic Affair, Jackson State University, for their support.

The completion of this Special Issue would not have been possible without the many hours contributed by all of the anonymous reviewers who dedicated their time and expertise to helping make this Special Issue a reality.

\section{Z. Younis ( $ه)$}

Health Economics \& Finance, College of Public Service, Jackson State University, Jackson, MS 39213, USA

e-mail: younis99@gmail.com

\section{Z. Younis}

Harvard University Asia Center, Cambridge, MA, USA 
Conflict of Interest Mustafa Z. Younis declares no conflict of interest.

Informed Consent As there is no person or personal data appearing in the paper, there is no one from whom a permission should be obtained in order to publish personal data.

Ethical Treatment of Experimental Subjects (Animal and Human) This article does not contain any studies with human or animal subjects performed by the author.

Mustafa Z. Younis was a member of the Executive Committee of the International Society for Research of Healthcare Financial Management and is an Editorial Board member or manuscript reviewer for several national and international journals. As an internationally recognized scholar, Dr Younis has authored and published over 100 articles and abstracts in refereed journals, and has presented at national and international conferences. He has collaborated with faculties from the School of Medicine at Jena University (Jena, Germany), as well as those from Turkey and the United Arab Emirates. He served with the American University of Beirut (Beirut, Lebanon) and the World Bank training workshops for health sector reforms in the Middle East, which involved training health administrators from several Middle Eastern countries. His present and future research activities focus on issues related to disparities and access in healthcare, cancer centers, long-term care and nursing homes; capital structure and debt financing for hospitals and healthcare organizations; examination of quality and efficiency in the healthcare sector; hospital mergers, conversions and changes of ownership; and hospital profitability. Dr Younis has administrative experience as Chair of the Department of Health Policy and Management at Florida International University (FL, USA) where he led the accreditation efforts for the Healthcare Management Program. He has strong research expertise in working with hospital and nursing home data to measure economic and financial performance. 